\title{
A New Alum Precipitated Oil Formulation Vis-a-Vis Alum Precipitated and Toxoid Enterotoxaemia Vaccines for the Enhanced and Sustained Immune Response against Epsilon Toxin in Sheep
}

A.K. Rai, V.K. Chaturvedi ${ }^{1}$, T.G. Sumithra, S.S. Chougule, B. Joseph, M.S. Murugan

10.18805/IJAR.B-4434

\begin{abstract}
Background: Enterotoxaemia represents one of the major limiting factors in small ruminant farming. Rapid lethal progression of the disease makes treatment impractical in most cases. Thus, suitable immunoprophylactic measures are necessary against this disease. The current study was aimed to test out the ability of novel alum precipitated oil adjuvant vaccine (AOV) for overcoming the difficulties associated with short-term immunity of current enterotoxaemia vaccines.

Methods: A new formulation named, AOV was prepared using a highly toxigenic strain of Clostridium perfringens type D. Immunogenicity and protective efficacy of this vaccine in comparison to presently available epsilon toxoid vaccine (TV) and alum precipitated vaccine (APV) was evaluated in the target species, sheep using indirect ELISA, mouse neutralization test (MNT).

Result: Among the three vaccines tested, AOV produced higher and persistent protective antibody titer up to 150 days post-immunization without any booster dose while APV and TV protected only up to $60^{\text {th }}$ and $45^{\text {th }}$ day respectively. All vaccinated animals remained healthy for the whole duration of the study with no systemic or local reactions. The present study delineates the superiority of AOV over presently available TV and APV for the prevention of an extremely lethal disease of sheep and goats.
\end{abstract}

Key words: Clostridium perfringens, ELISA, Enterotoxaemia, Mice neutralization test, Vaccine.

\section{INTRODUCTION}

Enterotoxaemia caused by Clostridium perfringens type D is worldwide in distribution (Radostitis et al. 2007) and represents one of the major limiting factors in small ruminant farming (Tooloei and Masodei 2008). The disease causes considerable loss in the sheep industry due to increased treatment costs, decreased productivity and high fatality rates among the affected animals (Greco et al. 2005). Tragically, rapid lethal progression makes treatment impractical in most cases (Aiello 2003). Thus, suitable immunoprophylactic measures are necessary to combat this disease (Rosskopf-Streicher et al. 2004). Though the disease can be prevented by epsilon toxoid (Lobato et al. 2010) it induces only short term immunity (Bernath et al. 2004), so double initial vaccination is currently recommended for both sheep and goats, followed by a booster every year in sheep (Blood et al. 1983) and every 3-4 months in goats (Smith and Sherman 1994). Therefore, the present vaccination strategy is not economical and often fails due to the difficulty in tracing the primary immunized animals for a booster dose. Thus, a single-shot enterotoxaemia vaccine would be an enormous benefit for sheep and goat breeders all over the world (Uzal et al. 1999) emphasizing the need to develop a new enterotoxaemia vaccine which induces a sustainable prolonged immunity.

The addition of adjuvants helps antigen to elicit an early high and long-lasting immune response with less amount. Aluminium salts are the most common adjuvants (Marrack
Division of Bacteriology and Mycology, Indian Veterinary Research Institute, Izatnagar, Bareilly-243 122, Uttar Pradesh, India.

${ }^{1}$ Division of Biological Products, Indian Veterinary Research Institute, Izatnagar, Bareilly-243 122, Uttar Pradesh, India.

Corresponding Author: A.K. Rai, Department of Veterinary Microbiology, College of Veterinary Science and Animal Husbandry, Jabalpur-482 001, Madhya Pradesh, India.

Email: ajay500rayss@gmail.com

How to cite this article: Rai, A.K., Chaturvedi, V.K., Sumithra, T.G., Chougule, S.S., Joseph, B. and Murugan, M.S. (2022). A New Alum Precipitated Oil Formulation Vis-a-Vis Alum Precipitated and Toxoid Enterotoxaemia Vaccines for the Enhanced and Sustained Immune Response against Epsilon Toxin in Sheep. Indian Journal of Animal Research. DOI: 10.18805/IJAR.B-4434.

Submitted: 24-02-2021 Accepted: 17-12-2021 Online: 28-02-2022

et al. 2009) but provide only a short duration of immunity. However, this duration can be prolonged by adding oil which also helps to cut down the required antigenic mass for effective immunity (Bincy et al. 2011). Atthi et al. (2001) showed that the oil adjuvanted hemorrhagic septicemia vaccine could protect cattle even after 24 months of post-vaccination. Since the major problem of enterotoxaemia vaccine lies with the duration of immunity, an attempt was made to develop a better enterotoxaemia vaccine using alum and oil as adjuvants and the efficacy was compared with presently available toxoid and alum precipitated vaccines in the target species, sheep. 


\section{MATERIALS AND METHODS}

The experiment was conducted in the Biological Products Division, ICAR-IVRI, Izatnagar, India during 2011-2013.

\section{Bacterial cultures}

In the present study, a highly toxigenic strain of $C$. perfringens type $\mathrm{D}$ was procured from the Division of Biological Standardization, Indian Veterinary Research Institute (IVRI), Izatnagar, Bareilly and was characterized by morphological, cultural and toxigenic properties. The molecular characterization was also done by polymerase chain reaction (PCR) using etx specific primers (F- 5'AAG GAT CCA AGT TTA GCA ATC GCA TCA GC3'; R - 5'TAC CTC GAG TTA TTT TAT TCC TGG TGC C3').

\section{Experimental animals}

Clinically healthy Swiss albino mice of either sex weighing not less than 18-20 grams were procured from the Lab Animal Resource (LAR) section of IVRI and maintained under standard conditions. The experimental procedures for care and maintenance of live animals were approved by the ICAR-Indian Veterinary Research Institute, Izatnagar, India (No: 4929 dated 29/11/2011).

Clinically healthy sheep without a history of vaccination against clostridial diseases maintained in the animal shed of Biological Products division, IVRI, Izatnagar were used for immunization. This large animal experimentation was approved by CPCSEA (Committee for the Purpose of Control and Supervision of Experiments on Animals, India). Twelve animals were divided randomly into 4 groups as one control and three vaccine groups.

\section{Production of vaccines}

\section{Toxoid vaccine (TV)}

The production medium (Jayaraman and Mallick 1961) was inoculated with an actively growing seed culture of $C$. perfringens type $D$ and incubated at $37^{\circ} \mathrm{C}$ for $24^{\text {th }}$. The culture was then tested for purity and aerobic sterility by microscopic and cultural examination. Subsequently, the $\mathrm{pH}$ of the culture filtrate was adjusted to alkaline and trypsinization was done to a final concentration of $0.25 \%$ and reincubated at $37^{\circ} \mathrm{C}$ for one hour. For getting the minimum lethal dose per $\mathrm{ml}$ of the product, random samples $(2 \mathrm{ml})$ from each flask were centrifuged and $0.1 \mathrm{ml}$ of various dilution of this supernatant was injected into two mice by intravenous route. The highest dilution producing lethality in both mice was taken as MLD/ $\mathrm{ml}$. Culture having above $3000 \mathrm{MLD} / \mathrm{ml}$ was formalized $(0.5 \%$ formalin) and incubated at $37^{\circ} \mathrm{C}$ for 15 days for detoxification. This was stored at $4^{\circ} \mathrm{C}$ and used as the TV.

\section{Alum precipitated vaccine (APV)}

After adjusting the $\mathrm{pH}$ of $100 \mathrm{ml}$ of TV to 6.5 , sterile $5 \%$ alum solution at $40^{\circ} \mathrm{C}$ was added to a final concentration of $1 \%$ in the vaccine and maintained at room temperature $\left(25^{\circ} \mathrm{C}\right)$ overnight with agitation. The product was labeled as APV and stored at $4^{\circ} \mathrm{C}$.

\section{Alum precipitated oil adjuvant vaccine (AOV)}

Nine parts of sterile liquid paraffin were transferred aseptically to a commercial blender and one part of sterile molten lanolin was added to it. This was mixed for 20 minutes at room temperature as follows. For mixing, a hundred $\mathrm{ml}$ of APV was added to the blender (Bajaj, India) and emulsification was carried out at room temperature giving 4 runs of 5 minutes each, with 5 minutes gap between each run at medium speed switch (approx. $10000 \mathrm{rpm}$ ) at room temperature. The vaccine was stored at $4^{\circ} \mathrm{C}$ overnight and re-emulsified on the next day.

\section{Quality testing of vaccines}

Sterility, safety and stability testing of all three vaccines were done. For testing sterility, $1 \mathrm{ml}$ of each vaccine was inoculated in $100 \mathrm{ml}$ of nutrient broth and blood agar plate and incubated at $37^{\circ} \mathrm{C}$ for three days. The safety of the vaccines was tested in six mice and a continuous 10 days observation was made. For stability testing, all three vaccines were kept at $4^{\circ} \mathrm{C}$ as well as at room temperature for 14 days before immunization.

\section{Immunization experiments}

Keeping antigenic mass constant each of all sheep in the designated groups was immunized with a single dose of $2.5 \mathrm{ml} \mathrm{TV}, 3 \mathrm{ml} \mathrm{APV}$ and $5 \mathrm{ml}$ AOV by deep intramuscular route. Serum collection was done on $0,7,14,21,30,60$, $90,120,150$ days post-vaccination (DPV) and stored at $-20^{\circ} \mathrm{C}$ until further use.

\section{Immune response studies}

\section{Preparation of antigen (Epsilon toxin)}

The clear supernatant from the production media was precipitated by $35 \%$ ammonium sulfate with stirring overnight. The precipitate after centrifugation was resuspended in PBS and dialyzed against $0.01 \mathrm{M}$ phosphate buffer ( $\mathrm{pH}$ 7.4). The dialyzed sample was concentrated using polyethylene glycol-6000. Further purification was done by DEAE-cellulose anion exchange chromatography. The peak fractions were pooled concentrated and checked by SDSPAGE, Western blotting and toxigenicity studies. Finally, the protein concentration of the formalized toxin was estimated.

\section{Production of hyperimmune serum}

Two $\mathrm{ml}$ of APV was injected subcutaneously in sheep as the first dose. Thereafter four injections of $3 \mathrm{ml}$ of TV were given at weekly intervals. After the $4^{\text {th }}$ injection, $2 \mathrm{ml}$ of blood was collected to check the antibody titer. The sheep with good titer were finally bled; serum was separated and stored at $-70^{\circ} \mathrm{C}$ until further use.

\section{Indirect ELISA}

The proper dilution of the antigen and serum was determined using the chequer-board method (Briggs and Skeeles 1984). Sera of sheep grown up in a clostridia-free environment was used as negative sera. 1: 10000 dilution of rabbit anti-sheep horseradish peroxidase (Sigma-Aldrich) was used as the 
secondary antibody. Titre of the individual serum sample was expressed in positive/negative ratio ( $\mathrm{P} / \mathrm{N}$ ratio). Statistical analysis was done using the program SPSS 17.

\section{Mouse neutralization test (MNT)}

In MNT, $1 \mathrm{ml}$ of pooled sera from each group was mixed with $1 \mathrm{ml}$ of epsilon containing $300 \mathrm{MLD}$ and kept at $37^{\circ} \mathrm{C}$ for half an hour. $0.2 \mathrm{ml}$ of the mixture was given intravenously to two mice. $0.1 \mathrm{ml}$ of the $300 \mathrm{MLD} / \mathrm{ml}$ toxin was injected into another two mice as control (British Pharmacopoeia 1993).

\section{RESULTS AND DISCUSSION \\ Characterization of Clostridium perfringens type D}

Clostridium perfringens type D showed typical morphological and cultural properties. Briefly, the organism appeared as large rectangular gram-positive bacilli, arranged singly, in short chains and sometimes in bundles. The organism was capsulated and non-motile. The organism was able to grow under microaerophilic conditions. The organism produced rich growth in Robertson's cooked meat broth at $37^{\circ} \mathrm{C}$ within 24-48 h. Molecular characterization yielded the desired 997bp product (Fig 1). The toxin titer was $3000 \mathrm{MLD} / \mathrm{ml}$.

\section{Quality testing of vaccines}

During purity testing of vaccines, it was found that the growth in the production flask was free from any contamination. Final vaccines inoculated in different media did not show any growth denoting their sterility. The sterility test in mice ensured the safety of all the prepared vaccines. AOV did not show the separation of different phases (oil and water) when kept at $4^{\circ} \mathrm{C}$ and room temperature indicating its stability.

\section{Immune response studies}

Vaccinated animals remained healthy for the whole duration of the study and all recorded normal weight gains. Moreover, none of the immunized animals showed untoward reactions at the injection site.

\section{Preparation of antigen (Epsilon toxin)}

In DEAE cellulose anion exchange chromatography, the fractions from tubes No. 5 to 15 were found to contain good concentrations of epsilon toxin (Fig 2). So these fractions were pooled. The protein concentration of the pooled fractions was $4.51 \mathrm{mg} / \mathrm{ml}$. On SDS-PAGE analysis of purified toxin, a single band of $32 \mathrm{KDa}$ was obtained (Fig 3). In Western blotting hyperimmune sera raised in sheep against TV and APV could detect the purified epsilon toxin (Fig 4).

\section{Indirect ELISA}

Optimal dilutions for antigen, sera and conjugate were found as $1: 200,1: 100$ and $1: 10000$ respectively. ELISA results are given in Table 1-4. AOV produced significant and persistent differences in titers. The highest $\mathrm{P} / \mathrm{N}$ value was observed in AOV on the $28^{\text {th }}$ DPV $(1.74 \pm 0.11)$ followed by APV $(1.66 \pm 0.05)$. There was a gradual rise from $7^{\text {th }}(1.26 \pm 0.06)$ to peak value on $28^{\text {th }}$ day $(1.74 \pm 0.11)$ after which it almost remained persistent up to $150^{\text {th }}$ DPV $(1.43 \pm 0.15)$ although there was a minor reduction. TV produced an early high $\mathrm{P} /$ $\mathrm{N}$ value on the $21^{\text {st }}$ day $(1.59 \pm 0.19)$ followed by a fast reduction on subsequent days. APV showed a gradual increase in $\mathrm{P} / \mathrm{N}$ value from the $14^{\text {th }}$ day $(1.35 \pm 0.11)$ to peak value on the $28^{\text {th }}$ day $(1.66 \pm 0.05)$ after that it showed decreasing trend and the $\mathrm{P} / \mathrm{N}$ value on the $150^{\text {th }}$ day was $1.07 \pm 0.06$

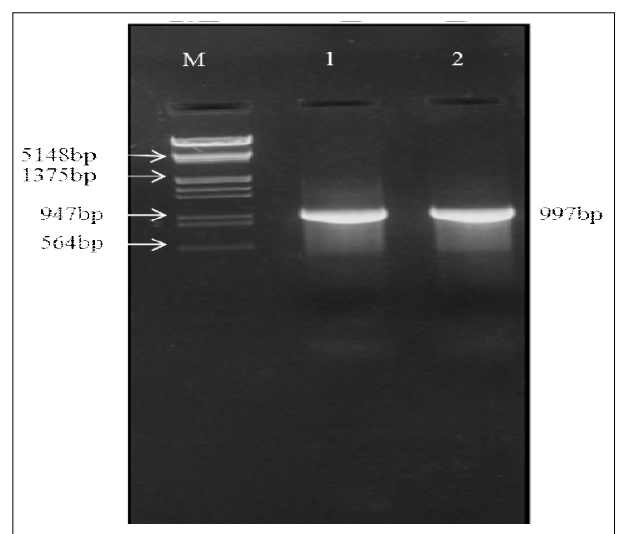

Fig 1: PCR amplification of etx gene. Lane 1, 2: Amplified etx, Lane M: DNA ladder ( $\lambda$ DNA/ EcoRI + HindIII double digest).

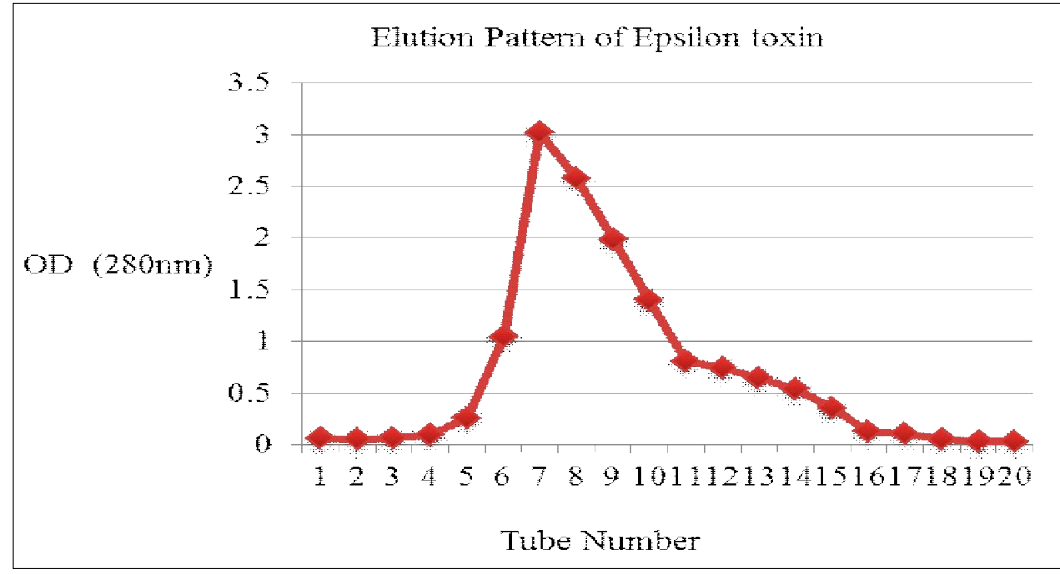

Fig 2: Elution pattern of epsilon toxin. 


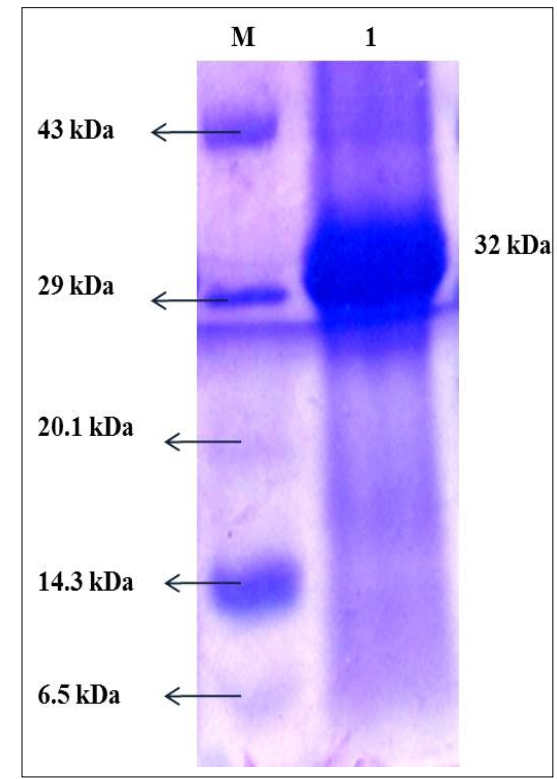

Fig 3: SDS-PAGE analysis of purified epsilon. Lane 1-3: Epsilon having $32 \mathrm{kDa}$ molecular weight, Lane M: Protein Marker.

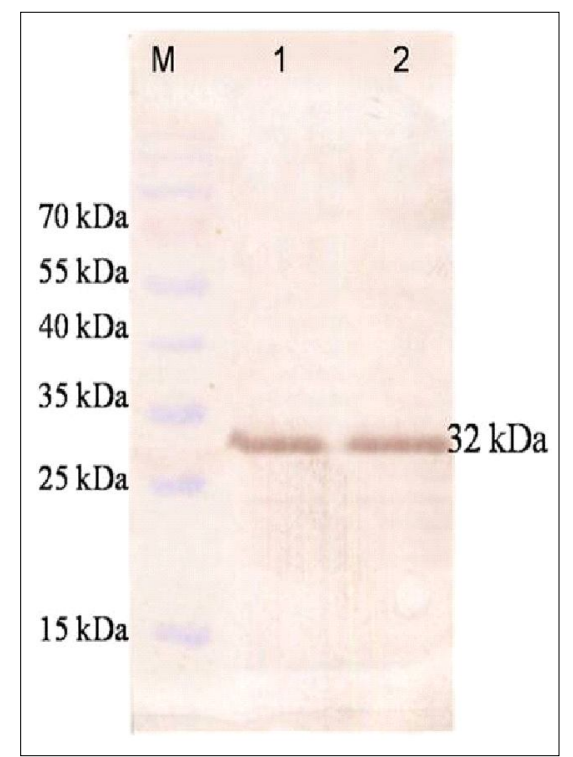

Fig 4: Western blotting of purified epsilon. Lane 1, 2: Purified Epsilon, Lane M: Protein Marker.

\section{Mouse neutralization test (MNT)}

MNT results of different vaccines are presented in Table 5. AOV showed positive MNT for the longest duration compared to other vaccines. In this case, mice did not die even after $150^{\text {th }}$ DPV. APV and TV showed the death of mice on the $90^{\text {th }}$ day and $60^{\text {th }}$ day respectively.

Vaccination remains the main prophylactic measure against enterotoxaemia (Rosskopf-Streicher et al. 2004), the disease-causing large economic losses in small ruminant farming (Veschi et al. 2008). However, a lengthy immunization schedule and difficulty in tracing the animal for booster dose necessitate further research focusing on the protection and duration of immunity. The attempts to improve vaccine efficacy using liposome formulation have not been successful (Uzal et al. 1999). Although incomplete Freund's adjuvant was successful in enhancing immune response to epsilon toxin (Uzal and Kelly 1998), this causes strong side effects such as abscess and granuloma thus recommended only for laboratories. Kumar et al. (2009) showed that there was no significant difference between alum precipitated and aluminium hydroxide gel adsorbed enterotoxaemia vaccines in sheep. Bincy et al. (2011) reported that the duration of immunity provided by alum precipitated oil adjuvant hemorrhagic septicemia vaccine was longer with less antigenic mass. Keeping these facts a new formulation alum precipitated oil adjuvant enterotoxaemia vaccine was made and compared with presently available toxoid and alum precipitated vaccines in the target species, sheep. As humoral immune response against epsilon is the key factor for protection against enterotoxaemia (Kerry et al. 1979), the humoral response was assayed.

The gold standard test for measuring the protective antibody titers against epsilon toxin is the toxin neutralization test in mouse (MNT). Ripley (1983) and Rahman et al. (2001) had used MNT to estimate immune response against enterotoxaemia vaccination. However, apart from the ethical considerations on the use of live animals, this suffers many other disadvantages such as variation in animal sensitivity, cumbersomeness, slowness and higher cost (Kozaki et al. 1979; Henderson 1984). Thus a simple in-vitro test is necessary for vaccine manufacturing laboratories, animal health authorities and researchers (Uzal et al. 1997). So indirect ELISA (Uzal et al. 1997; Bentancor et al. 2009) and competitive ELISA (Wood 1991) were proposed as alternative methods to measure anti-epsilon titers. Thus, an indirect ELISA was also used in the present study along with MNT to monitor the immune response.

During MNT, AOV showed a positive reaction up to the last period of observation i.e. 5 months DPV indicating the ability for producing a satisfactory level of protective immune responses from 7 to 150 days after inoculation with a single dose. APV elicited better protection than TV though it was less than AOV revealing the synergistic role of adjuvants in inducing better immunity. TV showed protection up to $45^{\text {th }}$ DPV which is in contradiction to the earlier reports of Jayaraman et al. 1971; Walker et al. 1992 and Bernath et al. 2004 who have reported protection only for 28 days with toxoid. Rahman et al. (2001) reported protection only up to 21 days after epsilon and beta toxoid vaccination. But Uzal et al. (1998) had reported that toxoid vaccines were giving variable immune responses.

In ELISA, the anti-epsilon antibody level was the highest among the AOV group followed by APV and TV. The AOV produced the highest ELISA titer and it persisted for a longer time than TV and APV. Though TV produced an early peak titer on the $21^{\text {st }}$ day compared to the other vaccines, there 
A New Alum Precipitated Oil Formulation Vis-a-Vis Alum Precipitated and Toxoid Enterotoxaemia Vaccines for the Enhanced...

was a rapid fall in titer on subsequent days. The titer on the $120^{\text {th }}$ day itself was less than the $7^{\text {th }}$ day thus revealing the reason for the short-term immunity provided by TV. This fast rise and fall of antibody titer revealed the rapid dispersion of free antigen from injection sites. In the case of AOV, there was a gradual rise in titer from $7^{\text {th }}\left(1.26 \pm .06^{\mathrm{a}}\right)$ to peak value on $28^{\text {th }}$ day $(1.74 \pm 0.11)$ which was slightly decreased at the $150^{\text {th }}$ DPV. APV elicited a better and persistent immune response than TV though it was less than AOV. This is in agreement with the observation of Kumar et al. (2009) who observed the enhancing effect of alum on anti-epsilon production. The gradual increase and decrease of antibody titer in the APV and AOV group might be due to the slow and gradual antigen release from the depot site which is the mechanism of adjuvanticity of aluminium compounds proposed by Edelman 1997. By the comparison between ELISA and MNT results it was found that a $P / N$ value of 1.26 or more is required to neutralize $150 \mathrm{MLD} / \mathrm{ml}$ of epsilon toxin.

Another important consideration when assessing adjuvanted vaccines, particularly for use in meat-producing animals, must be the degree of local reaction at the injection site. Surprisingly, in the present study, the immunized sheep did not show any untoward reactions at the injection site

Table 1: Anti-epsilon ELISA titres (P/N ratio) of sheep immunized with TV.

\begin{tabular}{lccccccccc}
\hline \multirow{2}{*}{ Animal } & \multicolumn{7}{c}{ DPV (Days post vaccination) } \\
\cline { 2 - 10 } & 7 & 14 & 21 & 28 & 45 & 60 & 90 & 120 & 150 \\
\hline 1 & 1.320 & 1.380 & 1.516 & 1.212 & 1.040 & 1.018 & 1.005 & 1.005 & 0.971 \\
2 & 1.228 & 1.250 & 1.300 & 1.198 & 1.117 & 1.070 & 1.026 & 1.005 & 1.001 \\
3 & 1.294 & 1.693 & 1.945 & 2.022 & 1.721 & 1.615 & 1.502 & 1.402 & 1.244 \\
Mean \pm SE & $1.280 \pm 0.03^{\mathrm{a}}$ & $1.441 \pm 0.13^{\mathrm{a}}$ & $1.590 \pm 0.19^{\mathrm{a}}$ & $1.480 \pm 0.27^{\mathrm{a}}$ & $1.290 \pm 0.22^{\mathrm{a}}$ & $1.200 \pm 0.19^{\mathrm{a}}$ & $1.18 \pm 0.16^{\mathrm{a}}$ & $1.140 \pm 0.13^{\mathrm{a}}$ & $1.070 \pm 0.09^{\mathrm{a}}$ \\
\hline
\end{tabular}

a represents no significant difference.

Table 2: Anti-epsilon ELISA titres (P/N ratio) of sheep immunized with APV.

\begin{tabular}{lccccccccc}
\hline \multirow{2}{*}{ Animal } & \multicolumn{7}{c}{ DPV(Days post vaccination) } \\
\cline { 2 - 9 } & 7 & 14 & 21 & 28 & 45 & 60 & 90 & 120 & 150 \\
\hline 4 & 1.141 & 1.339 & 1.435 & 1.700 & 1.660 & 1.431 & 1.331 & 1.193 & 1.186 \\
5 & 1.481 & 1.547 & 1.673 & 1.721 & 1.457 & 1.421 & 1.194 & 1.147 & 1.047 \\
6 & 1.156 & 1.166 & 1.506 & 1.548 & 1.406 & 1.381 & 1.092 & 0.994 & 0.991 \\
Mean+SE & $1.26 \pm 0.11^{\text {abc }}$ & $1.35 \pm 0.11^{\text {bcd }}$ & $1.54 \pm 0.07^{\text {de }}$ & $1.66 \pm 0.05^{\mathrm{e}}$ & $1.51 \pm 0.07^{\text {de }}$ & $1.41 \pm 0.02^{\text {cd }}$ & $1.20 \pm 0.07^{\text {abc }}$ & $1.11 \pm 0.06^{\text {ab }}$ & $1.07 \pm 0.06^{\mathrm{a}}$ \\
\hline
\end{tabular}

a, b, c, d and e represents significant difference level 1, 2,3, 4 and 5.

Table 3: Anti-epsilon ELISA titres (P/N ratio) of sheep immunized with AOV.

\begin{tabular}{lccccccccc}
\hline \multirow{2}{*}{ Animal } & \multicolumn{7}{c}{ DPV (Days post vaccination) } \\
\cline { 2 - 10 } & 7 & 14 & 21 & 28 & 45 & 60 & 90 & 120 & 150 \\
\hline 7 & 1.248 & 1.274 & 1.416 & 1.645 & 1.716 & 1.656 & 1.472 & 1.228 & 1.228 \\
8 & 1.305 & 1.416 & 1.660 & 1.964 & 1.665 & 1.630 & 1.934 & 1.822 & 1.723 \\
9 & 1.202 & 1.229 & 1.447 & 1.620 & 1.630 & 1.624 & 1.533 & 1.330 & 1.330 \\
Mean \pm SE & $1.26 \pm 0.06^{\mathrm{a}}$ & $1.31 \pm 0.06^{\mathrm{a}}$ & $1.51 \pm 0.08^{\mathrm{ab}}$ & $1.74 \pm 0.11^{\mathrm{b}}$ & $1.67 \pm 0.02^{\mathrm{b}}$ & $1.63 \pm .01^{\mathrm{ab}}$ & $1.63 \pm 0.14^{\mathrm{ab}}$ & $1.46 \pm 0.18^{\mathrm{ab}}$ & $1.43 \pm 0.15^{\mathrm{ab}}$ \\
\hline
\end{tabular}

${ }^{\mathrm{a}}$ and ${ }^{\mathrm{b}}$ represents significant difference level 1 and 2 .

Table 4: Anti-epsilon ELISA titres (P/N ratio) of sheep immunized with different vaccines.

\begin{tabular}{|c|c|c|c|c|c|c|c|c|c|}
\hline \multirow{2}{*}{ Vaccines } & \multicolumn{9}{|c|}{ DPV (Days post vaccination) } \\
\hline & 7 & 14 & 21 & 28 & 45 & 60 & 90 & 120 & 150 \\
\hline TV & $1.28 \pm 0.03^{a}$ & $1.441 \pm 0.13^{a}$ & $1.590 \pm 0.19^{a}$ & $1.480 \pm 0.27^{\mathrm{a}}$ & $1.290 \pm 0.22^{\mathrm{a}}$ & $1.200 \pm 0.19^{a}$ & $1.18 \pm 0.16^{a}$ & $1.140 \pm 0.13^{a}$ & $1.070 \pm 0.09^{\mathrm{a}}$ \\
\hline APV & $1.26 \pm 0.11^{\mathrm{abc}}$ & $1.35 \pm 0.11^{\mathrm{bcd}}$ & $1.54 \pm 0.07^{\mathrm{de}}$ & $1.66 \pm 0.05^{\mathrm{e}}$ & $1.51 \pm 0.07^{\mathrm{de}}$ & $1.41 \pm 0.02^{\mathrm{cd}}$ & $1.20 \pm 0.07^{a b c}$ & $1.11 \pm 0.06^{\mathrm{ab}}$ & $1.07 \pm 0.06^{\mathrm{a}}$ \\
\hline AOV & $1.26 \pm 0.06^{\mathrm{a}}$ & $1.31 \pm 0.06^{\mathrm{a}}$ & $1.51 \pm 0.08^{\mathrm{ab}}$ & $1.74 \pm 0.11^{b}$ & $1.67 \pm 0.02^{b}$ & $1.63 \pm .01^{\mathrm{ab}}$ & $1.63 \pm 0.14^{\mathrm{ab}}$ & $1.46 \pm 0.18^{\mathrm{ab}}$ & $1.43 \pm 0.15^{\mathrm{ab}}$ \\
\hline
\end{tabular}

Table 5: Mice neutralization test (MNT).

\begin{tabular}{lccccccccc}
\hline \multirow{2}{*}{ Vaccines } & \multicolumn{10}{c}{ DPV (Days post vaccination) } \\
\cline { 2 - 9 } & 7 & 14 & 21 & 28 & 45 & 60 & 90 & 120 & 150 \\
\hline TV & ND & ND & ND & ND & ND & D & D & D & D \\
APV & ND & ND & ND & ND & ND & ND & D & D & D \\
AOV & ND & ND & ND & ND & ND & ND & ND & ND & ND \\
\hline
\end{tabular}

${ }^{*}$ ND- Not died, ${ }^{* *}$ D- Died, ${ }^{* *}$ In all tables DPV- Days post vaccination. 
maybe because of the deep intramuscular administration. On contrary to this, some authors (Green et al. 1987; Stokka et al. 1994; Mamak and Aytekin 2009) observed adverse reactions following enterotoxaemia vaccination.

\section{CONCLUSION}

The findings of this study, thus, unfolded the synergistic role of adjuvants in enterotoxaemia vaccination along with the development of oil adjuvant alum precipitated enter otoxaemia vaccine which can give better and prolonged immune response without any side effects. However, a better understanding of the high level of protection observed in AOV needs further exploration on a large scale and on various molecular determinants. Further studies are also required for increasing the epsilon toxoid antigenic mass and reducing the dose of oil-based vaccine so that vaccine load can be reduced to $1 \mathrm{ml}$ of final formulation with equivalent immune response. The present limitations of the current vaccines can be very well resolved with this formulation and field application of such vaccine may reduce the incidence of disease to the lowest possible level. Such a study can lead to the further development of these better vaccines so that these can be finally transferred to the hands of farmers.

\section{ACKNOWLEDGEMENT}

The authors are grateful to the Director and Joint Directors (Academic and Research) of the Institute (Indian Veterinary Research Institute, Izatnagar, Bareilly, India) for providing research facilities to carry out the investigation.

\section{REFERENCES}

Aiello, S.E. (2003). The Merck Veterinary Manual. $8^{\text {th }}$ ed. Merck and Co., Whitehouse Station, New Jersey, USA: Merck Publishing Group.

Atthi, R., Rungvetvuthivithaya, V., Lertlimchalalai, N., Teerathavorawn, W., Ratchanee, A., Vuthiporn, R., Niteth, R. and Wanchai, T. (2001). Evaluation of immunity of haemorrhagic septicaemia oil adjuvant vaccine in cattle. The Journal of Thai Veterinary Medical Association. 52: 223-30.

Bentancor, A.B., Halperin, P, Flores, M. and Iribarren, F. (2009). Antibody response to the epsilon toxin of Clostridium perfringens following vaccination of Lama glama crias. Journal of Infection in Developing Countries. 3: 624-27.

Bernath, S., Fabian, K., Kadar, S.G., Barna, T. (2004). Optimum time interval between first vaccination and booster of sheep for Clostridium perfringens type D. Acta Veterinaria. 73: 473-75.

Bincy Joseph., Chaturvedi, V.K., Gupta, P.K., Sridevi, R. and Sumithra, T.G. (2011). Comparative studies on the immunogenicity of new aluminium hydroxide gel saponin vaccine with aluminium hydroxide gel and oil adjuvant vaccine for haemorrhagic septicaemia. Indian Journal of Comparative Microbiology, Immunology and Infectious Diseases. 31: 51-63.

Blood, D.C., Radostits, O.M. and Henderson, J.A. (1983). Veterinary Medicine: A textbook of the diseases of cattle, sheep, goats and horses. 6th edition, Bailliere Tindall, Oxford.
Briggs, D.J. and Skeeles, J.K. (1984). An enzyme linked immuno sorbent assay for detecting antibodies to Pasteurella multocida in chickens. Avian Diseases. 28: 208-15.

British Pharmacopoeia (Veterinary) (1993). HMSO, London.

Edelman, R. (1997). Adjuvants for the Future, In: New Generation Vaccines. [Levine, M.M., Woodrow, G.C., Kaper, J.B. and Cobon, G.S. (Eds.)] $2^{\text {nd }}$ edition, Marcel Dekker Inc., New York, USA.

Green, D.S., Green, M.J., Hillyer, M.H. and Morgan, K.L. (1987). Injection site reaction and antibody response in sheep and goats after the use of multivalent clostridial vaccines. Veterinary Record. 120: 436-39.

Henderson, T.G. (1984). The detection of Clostridium perfringens type $D$ enterotoxin in the intestinal contents of animals by counter immuno electophoresis. New Zealand Journal of Science. 27: 423-26.

Jayaraman, M.S. and Mallick, B.B. (1961). Clostridium welchii type $D$ infection (enterotoxaemia) in sheep and its control. Indian Veterinary Journal. 38: 226-33.

Jayaraman, M.S., Harbola, P.C., Kathuria, B.K. and Kumar, P.N. (1971). Development of a purified multicomponent clostridial vaccine. Indian Veterinary Journal. 48: 663-72.

Kerry, J.B., Craig, G.R. (1979). Field studies in sheep with multicomponent clostridial vaccines. Veterinary Record. 105: $551-54$.

Kozaki. S., Dufrenne, J., Hagenaars, A.M. and Notermans, S. (1979). Enzyme linked immunosorbent assay (ELISA) for the detection of Clostridium perfringens type B toxin. Japanese Journal of Medical Science and Biology. 32: 199-05.

Kumar, T.P., Sunitha, G., Krishnamohan, A.V and, Reddy, G.H. (2009). Comparative efficacy of alum precipitated and aluminium hydroxide gel adsorbed Enterotoxaemia vaccines in sheep. Indian Veterinary Journal. 86: 661-62.

Lobato, F.C.F., Catarina, G.R.D., Lima, R.A., Assis, P.S., Pires, R.O.S., Silva, F.M., Salvarani, A.O., Carmo, C.C. and Evanguedes K. (2010). Potency against enterotoxemia of a recombinant Clostridium perfringens type $D$ epsilon toxoid in ruminants. Vaccine. 28: 6125-27.

Mamak, N. and Aytekin, I., 2009. Fatal adverse reactions of enterotoxaemia vaccine in a sheep flock. Journal of Animal and Veterinary Advances. 8: 2388-91.

Marrack, P., McKee, A.S. and Munks. M.W. (2009). Towards an understanding of the adjuvant action of aluminium. Nature Reviews Immunology. 9: 287-93.

Radostitis, O.M., Gay, C.C., Hinchcliff, K.H. and Constable, P.D. (2007). Veterinary Medicine. $10^{\text {th }}$ edition. Saunders Elsevier, London, pp. 773-79.

Rahman, M.S., Baek, B.K., Hong, S.T. and Lee, L.H. (2001). Antibody responses in buffalos immunized with Clostridium perfringens beta and epsilon toxoids. Veterinary Medicine Czech. 46: 241-43.

Ripley, P.H. (1983). Immunization schedule for the prevention of infectious necrotic enteritis caused by Clostridium perfringens type $C$ in piglets. Veterinary Record. 112: 201-02.

Rosskopf-Streicher, U., Volkers, P., Noeske, K., Werner, E. (2004). Quality assurance of $C$. perfringens epsilon toxoid vaccines, ELISA versus mouse neutralisation test. Altex. 3: 65-69. 
A New Alum Precipitated Oil Formulation Vis-a-Vis Alum Precipitated and Toxoid Enterotoxaemia Vaccines for the Enhanced...

Smith, M.C., Sherman, D.M. (1994). Goat Medicine, Lea and Febiger, Pennsylvania, pp: 620.

Stokka, G.L., Edwards, A.J., Spire, M.F., Brandt, R.T., Smith, J.E. (1994). Inflammatory response to clostridial vaccines in feedlot cattle. Journal of the American Medical Association. 204: 9.

Tooloei, C.M., Masodei, M.H. (2008). The distribution and prevalence rate of enterotoxemia in sheep in East Azerbaijan Province, Northwestern Iran, in Spring 2008. Journal of Animal Veterinary Advances. 7: 1434-39.

Uzal, A., Bodero, D.A.V., Kelly, W.R. (1998). Variability of serum antibody responses of goat kids to a commercial Clostridium perfringens epsilon toxoid vaccine. Veterinary Record. 143: 472-74.

Uzal, F.A., Kelly, W.R. (1998). Protection of goats against experimental enterotoxemia by vaccination with Clostridium perfringens type $\mathrm{D}$ epsilon toxoid. Veterinary Record. 142: 722-25.

Uzal, F.A., Nielsen, K., Kelly, W.R. (1997). Detection of Clostridium perfringens type $D$ epsilon antitoxin in serum of goats by competitive and indirect ELISA. Veterinary Microbiology. 51: 223-31.
Uzal, F.A., Wong, J.P., Kelly, W.R., Priest, J. (1999). Antibody response in goats vaccinated with liposome-adjuvanted Clostridium perfringens type $\mathrm{D}$ epsilon toxoid. Veterinary Research Communication. 23: 143-50.

Veschi, J.L., Bruzzone, O.A., Losada-Eaton, D.M., Dutra, I.S., Fernandez-Miyakawa, M.E. (2008). Naturally acquired antibodies against Clostridium perfringens epsilon toxin in goats. Veterinary Immunology and Immunopathology. 125: 198-02.

Walker, P.D. (1992). Bacterial vaccines: old and new, veterinary and medical. Vaccine. 10: 977-90.

Wood, K.R. (1991). An alternative to the toxin neutralization assay in mice for the potency testing of the Clostridium tetani, Clostridium septicum, Clostridium novyi type B and Clostridium perfringens type $\mathrm{D}$ epsilon components of multivalent sheep vaccines. Biologicals. 19: 281-86. 